\title{
A cross-sectional analysis of the association between age and gender and prescribed minimum benefit chronic disease list conditions among South Africans with concomitant hypertension, diabetes and dyslipidaemia.
}

\author{
Johanita Burger ${ }^{1}$, Martie Lubbe ${ }^{1}$, Jan Serfontein ${ }^{1}$, Suria Ellis ${ }^{2}$
}

1. North-West University, Medicine Usage in South Africa (MUSA)

2. North-West University, Faculty Natural Sciences, Statistical Consultation

\begin{abstract}
:
Background: Prescribed Minimum Benefit Chronic Disease List (PMB CDL) conditions are a regulated list of conditions most common to South Africa.

Objectives: To investigate the prevalence and association between PMB CDL conditions and age and gender among patients with concomitant hypertension, diabetes and dyslipidaemia.

Methods: The study population consisted of patients $(n=17$ 866) with a prescription containing at least one co-prescribed antilipemics, antihypertensive and antidiabetic (identified using the MIMS Desk Reference). ICD-10 codes on claims for PMB CDL conditions were counted.

Results: $39.5 \%$ of patients had a PMB CDL condition. Women had higher odds for hypothyroidism (OR 6.30, 95\% CI; 5.52, $7.19, p<0.001)$ and lower odds for coronary artery disease (CAD) (OR 0.63, 95\% CI; 0.55, 0.72, p < 0.001) than men. In combination with hypothyroidism the odds for CAD were reversed and strongly increased; 3.54 (95\% CI; 2.38, 5.25, p < 0.001). The odds for females having cardiac failure (CF) was insignificant and low (OR 0.87, 95\% CI; 0.75, 1.01, $\mathrm{p}=0.063$ ); however combined with hypothyroidism, the odds increased to 5.35 (95\% CI; 3.52, 8.13, p < 0.001).

Conclusion: Hypothyroidism was an important discriminating factor for co-morbidity in women with concomitant hypertension, diabetes and dyslipidaemia, in particular with cardiovascular disease.

Keywords: Concomitant hypertension, diabetes and dyslipidaemia, South Africa, prescribed minimum benefit chronic disease list (PMB CDL) conditions.

DOI: https://dx.doi.org/10.4314/ahs.v17i1.12

Cite as: Burger J, Lubbe M, Serfontein J, Ellis S. A cross-sectional analysis of the association between age and gender and prescribed minimum benefit chronic disease list conditions among South Africans with concomitant hypertension, diabetes and dyslipidaemia. Afri Health Sci. 2017;17(1): 88-98. https://dx.doi.org/10.4314/ahs.v17i1.12
\end{abstract}

\section{Introduction}

In a commentary published in The Lancet, Salisbury ${ }^{1}$ described the existence of multi-morbidity (defined as "several chronic disorders in one individual") as the "norm rather than the exception", citing the management of these patients as the "most important task facing health services in developed countries." Salisbury described several reasons for the importance of multi-morbidity, including an ageing population with a large number of chronic illnesses, greater longevity, and a subsequent rapidly growing need for health care services associated with an increasing financial burden.
Corresponding author:
Johanita Burger,
North-West University,
Medicine Usage in South Africa (MUSA)
Email: johanita.burger@nwu.ac.za

Developing countries such as South Africa are not exempt from the effects of an aging population as shown by the United Nations population statistics. ${ }^{2}$ Compared to the $5 \%$ for the African continent en bloc, the percentage of South Africans over the age of 60 years in 2012 was noticeably higher at $9 \%$, displaying similar levels of aging as nations in Central America, Micronesia, Polynesia and South-Eastern Asia. ${ }^{2}$ Based on statistics from the World Health Organization, the burden from chronic disease (mainly cardiovascular diseases, cancers, chronic respiratory diseases and diabetes) in South Africa are two to three times higher than that in developed countries. ${ }^{3}$ The first South African National Health and Nutrition Examination Survey (SANHANES-1) ${ }^{4}$ conducted in 2012, showed that elderly South Africans (65 years and older) in general had the highest self-reported rates for chronic conditions. At the national level, $16.5 \%$ of all respondents indicated that they had high blood pressure, followed by diabetes $(5.0 \%)$, high blood cholesterol $(4.2 \%)$, 
heart disease $(2.2 \%)$ and stroke (1.8\%). Females had significantly higher self-reported rates than males; however, the rates of all chronic conditions tended to increase with age among both sexes. ${ }^{4}$ Similar to several developed countries, ${ }^{5-9}$ approximately half of elderly patients in the private health sector of South Africa suffer from more than one chronic disease, with some being diagnosed for up to eleven conditions. ${ }^{10}$

The South African private health sector is administered largely by health insurance schemes (provided by medical schemes, i.e. medical insurance packages made up from of a group of participating members). This sector serves less than $20 \%$ of the population's needs, yet consumes more than $50 \%$ (maybe as high as $80 \%$ ) of the total health care expenditure in South Africa or approximately seven times more per capita than the public sector. ${ }^{11}$ Beneficiaries 65 years old or older represent $6.5 \%$ of this population. ${ }^{12}$ Already in 2009 , the burden of chronic diseases in South Africa was noted to be on the rise resulting in a higher demand for chronic care. ${ }^{13}$ To curb the expenditure on health care in the private sector the South African Government enacted a range of regulations, inter alia the application of a Prescribed Minimum Benefit Chronic Disease List (or PMB CDL). By definition, the PMB CDL, as a feature of the Medical Schemes Act, 131 of 1998 , is a regulated compilation of 25 conditions requiring treatment for over 12 months that are most common to the country, are considered to be life-threatening, and conditions where cost-effective treatment will sustain and improve the quality of the member's life. Medical schemes are obliged to cover the costs related to the diagnosis, treatment and ongoing care of these conditions, to the extent that this is provided for by way of a therapeutic algorithm for the specified condition. ${ }^{14-15}$

Chronic conditions often cluster in the elderly, ${ }^{16}$ because of common pathways. ${ }^{17}$ The metabolic syndrome is typically characterized by the variable clustering of metabolic abnormalities or risk factors that increases a person's risk for atherosclerotic cardiovascular disease. ${ }^{18}$ According to the American Heart Association/National Heart, Lung and Blood Institute (AHA/NHLBI $)^{19}$, the presence of any three of five traits can constitute a diagnosis, from: (1) elevated waist circumference $(\geq 102 \mathrm{~cm}$ in men and $\geq 88 \mathrm{~cm}$ in women); (2) elevated triglycerides of $\geq 1.7$ $\mathrm{mmol} / \mathrm{L}$ (or on drug treatment for elevated triglycerides); (3) reduced HDL cholesterol $<1.03 \mathrm{mmol} / \mathrm{L}$ in men and $<1.3 \mathrm{mmol} / \mathrm{L}$ in women (or on drug treatment for reduced HDL cholesterol); (4) elevated blood pressure measured as systolic blood pressure $\geq 130 \mathrm{mmHg}$ or diastolic blood pressure $\geq 85 \mathrm{mmHg}$ (or on antihypertensive drug treatment in a patient with a history of hypertension); and (5) elevated fasting glucose $\geq 5.6 \mathrm{mmol} / \mathrm{L}$ (or on drug treatment for elevated glucose).$^{19}$

The prevalence of PMB CDL conditions in South African patients with metabolic syndrome-traits is not known. ${ }^{20-23}$ The present study contributes to bridging the knowledge gap by aiming to investigate the prevalence of PMB CDL conditions in South African private health care patients with metabolic syndrome-traits (i.e. concomitant hypertension, diabetes and dyslipidaemia), and association between the PMB CDL conditions and age and gender among these patients.

\section{Methods \\ Design, data source and study population}

The flow diagram of selection of eligible patients for analysis is shown in Figure 1. A cross-sectional analysis was conducted using a database obtained from a South African Pharmaceutical Benefit Management company (PBM). The database for the period 1 January to 31 December 2008 contained pharmaceutical claims information for a total of 974497 patients (538 254 women; 436243 men), representing $12.4 \%$ of the total medical scheme industry across South Africa during 2008. ${ }^{24}$ Using drug prescriptions as surrogates for disease state, we selected all patients that had a paid claim for a prescription containing one or more co-prescribed antilipidemics, antihypertensives and antidiabetics. Antilipodemics, and antidiabetics were identified using the annual MIMS Desk Reference (MDR) ${ }^{25}$ for 2008. These claimants, were regarded as patients with concomitant hypertension, diabetes and dyslipidaemia ( $\mathrm{n}=17$ 866; male-to-female ratio 1.17, mean age 63.7 (SD 11.98) years) (Figure 1). 


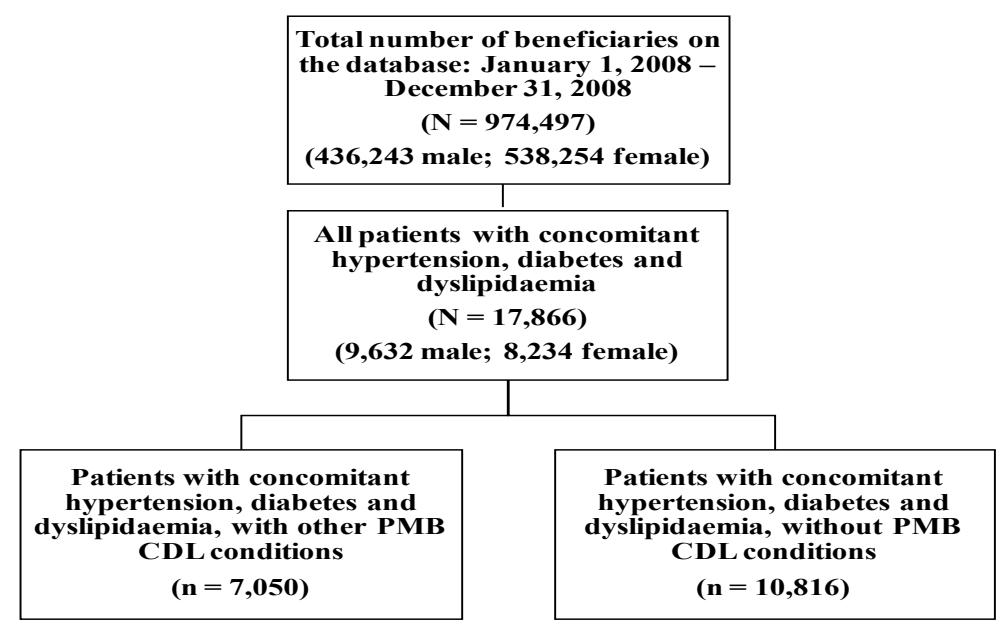

Figure 1. The flow diagram of selection of eligible patients for analysis

Legend: PMB CDL conditions = Prescribed Minimum Benefit Chronic Disease List conditions.

We queried data fields for patient demographic information (patients' member number and dependent code, gender and date of birth), and pertinent prescription information (such as drug trade name, date of treatment and ICD-10 code per claim). The variables 'date of birth' and 'date of treatment' were used to calculate the age of patients on the day of treatment. ICD-10 codes specified for reimbursement purposes on paid prescription claims were used to identify PMB CDL conditions in the study population. Presence of PMB CDL conditions were further used to categorize metabolic syndrome patients with concomitant hypertension, diabetes and dyslipidaemia into groups, viz. those with PMB CDL conditions (one or multiple) and those without (Fig. 1).

\section{Identification of PMB CDL conditions}

PMB CDL conditions were identified based on presence of the following ICD-10 codes on claims reimbursed from patients' PMB benefits: Addison's disease (ICD10 code E27.1), asthma (J45, J45.8), bronchiectasis (J47, Q33.4), cardiac failure (I50, I50.0, I50.1), cardiomyopathy (I42, I42.0, I25.5), chronic obstructive pulmonary disease (J43, J44), chronic renal disease (N03, N11, N18), coronary artery disease (I20, I20.0, I25), Crohn's disease (K50, K50.8), diabetes insipidus (E23.2), dysrhythmias (I47, I47.2, I48), epilepsy (G40, G40.8), glaucoma (H40, Q15.0), hemophilia (D66, D67), hypothyroidism (E02, E03, E03.8), multiple sclerosis (G35), Parkinson's disease (G20, G21), rheumatoid arthritis (M05, M06, M08.0), schizophrenia (F20), systemic lupus erythematosus (M32, L93, L93.2) and ulcerative colitis (K51, K51.9). ${ }^{14,15}$

\section{Statistical analysis}

Variables were characterized using 95\% confidence intervals and descriptive statistics such as proportions/ratios for categorical variables, and means and standard deviations for continuous variables. An independent two-sample $t$-test (assuming unequal variances) was used to assess the statistical significance of the age difference between men and women. Spearman's rank-order correlation test was performed to assess the relationship between the number of PMB CDL conditions per patient and patients' age. Cross-tabulation with chi-squared statistics was used to assess the association between the number of PMB CDL conditions per patient and patients' gender.

We further performed logistic regression analysis to assess the association between the specific PMB CDL condition and patients' gender, and calculated odds ratios (ORs) and associated $95 \%$ Wald confidence intervals $(95 \% \mathrm{CI})$. For the univariate model, the independent variable was gender [(female (1), male (0)], with each PMB CDL condition as the dependent variable [with present (1), absent (0)]. Prevalence of chronic disease, ${ }^{26-33}$ in general, increases with age. For the adjusted model, we therefore included age as co-variate. Age-adjusted odds ratios, however, did not differ from the crude odds ratio by more than $10 \%$.

Because statistical significance tests yielded small $p$-values (indicating significance) in most tests, we focused our interpretation on effect sizes which is independent of units and sample size. Cohen's $d$-value was used to evaluate mean differences between groups (with significance de- 
fined as a level of at least 0.8 ). Spearman's correlation coefficient was used for the strength of association between ranked variables, and Cramér's $V$ statistics (defined as a level of at least 0.5) was used for associations between categorical variables. Odds ratios in contingency tables were interpreted using guidelines by $\mathrm{Steyn}^{34}$, where an OR $>2$ was interpreted as a moderate effect, and larger than 3.64 as practically significant. Statistical analyses were performed using SAS Software, version 9.3. ${ }^{35}$

\section{Ethical considerations}

The study was conducted with the approval of the Research Ethics Committee of North-West University (Potchefstroom campus), and the board of directors of the PBM. As per confidentiality agreement with the PBM supplying the data, all identifying information about beneficiaries, medical schemes, health plans, service providers and prescribers were encrypted or removed by the PBM before data was released for analysis.

\section{Results}

Table 1 shows the basic demographic characteristics of the study population. A total of 7,050 patients with concomitant hypertension, diabetes and dyslipidaemia
(39.5\%) had one or more PMB CDL conditions during the study period. Women $(\mathrm{n}=3,791)$ of this group of patients were on average significantly older than men (n $=3,259)$ at $67.58 \pm 11.9(95 \% \mathrm{CI}, 67.2-68.0)$ and 66.74 \pm 11.4 (95\% CI, 66.3-67.1) years, respectively. However, Cohen's $d$-value showed no practical difference $(d$-value $=0.07$ ).

Of those with PMB CDL conditions, 5,061 (71.8\%) had one condition, a further 1,626 (23.1\%) had two conditions, $302(4.3 \%)$ had three conditions, $52(0.7 \%)$ had four conditions and a further 9 patients had the maximum of five PMB CDL conditions (average number of PMB CDL conditions per patient $1.34 \pm 0.61,95 \%$ CI; 1.33, 1.36). The most prevalent PMB CDL conditions overall were hypothyroidism, coronary artery disease and cardiac failure, experienced by $35.5 \%, 23.5 \%$, and $22.6 \%$ of patients from the study population with PMB CDL conditions ( $\mathrm{n}=7,050)$, respectively (Table 1$)$. The relationship between the number of PMB CDL conditions per patient and patients' age was significant, however, Spearman's rank-order correlation test showed that this association was weak ( $\mathrm{rs}=0.205, p<0.001$ ). Cross-tabulation further showed that there was no association between the number of PMB CDL conditions per patient and patients' gender ( $p=0.802$, Cramér's $V=0.01$ ) 
Table 1. Descriptive statistics

\begin{tabular}{|c|c|c|c|c|}
\hline Variable & Females & Males & $\begin{array}{l}p- \\
\text { value }\end{array}$ & $\begin{array}{l}\text { Effect } \\
\text { size }\end{array}$ \\
\hline \multicolumn{5}{|l|}{$\begin{array}{l}\text { Study population } \\
(\mathrm{N}=17,866)\end{array}$} \\
\hline Total nr of patients, $\mathrm{n}(\%)$ & $8,234(46.1)$ & $9,632(53.9)$ & & \\
\hline Age, mean $\pm \mathrm{SD}[95 \% \mathrm{CT}]$ & $\begin{array}{l}65.04 \pm 12.3 \\
{[64.865 .3]}\end{array}$ & $\begin{array}{l}62.60 \pm 11.6 \\
{[62.462 .8]}\end{array}$ & $<0.001$ & $0.19 *$ \\
\hline \multicolumn{5}{|l|}{$\begin{array}{l}\text { Patients with PMB CDL conditions } \\
(n=7050)\end{array}$} \\
\hline Total nr of patients, $\mathrm{n}(\%)$ & $3,791(53.8)$ & $3,259(46.2)$ & & \\
\hline Age, mean $\pm \mathrm{SD}[95 \% \mathrm{CI}]$ & $\begin{array}{l}67.58 \pm 11.9 \\
{[67.268 .0]}\end{array}$ & $\begin{array}{l}66.74 \pm 11.4 \\
{[66.367 .1]}\end{array}$ & 0.003 & $0.07 *$ \\
\hline $\begin{array}{l}\text { Average nr of PMB CDL per patient, } \\
\text { mean } \pm \mathrm{SD}[95 \% \mathrm{CI}]\end{array}$ & $\begin{array}{l}1.34 \pm 0.6 \\
{[1.321 .36]}\end{array}$ & $\begin{array}{l}1.35 \pm 0.6 \\
{[1.321 .37]}\end{array}$ & 0.823 & $0.02 *$ \\
\hline \multicolumn{5}{|l|}{$\begin{array}{l}\text { Prevalence of PMB CDL conditions } \\
\text { overall }\end{array}$} \\
\hline Addison's disease, n (\%) & $4(0.1)$ & $6(0.2)$ & 0.529 & $0.010^{* *}$ \\
\hline Asthma, n $(\%)$ & $522(13.8)$ & $491(15.1)$ & 0.122 & $0.018^{* *}$ \\
\hline Bronchiectasis, n (\%) & 0 & $1(0.03)$ & 0.462 & $0.013 * *$ \\
\hline Cardiac failure, $\mathrm{n}(\%)$ & $754(19.9)$ & $839(25.7)$ & $<0.001$ & $0.070^{* *}$ \\
\hline Cardiomyopathy, n (\%) & $248(6.5)$ & $369(11.3)$ & $<0.001$ & $0.084 * *$ \\
\hline $\begin{array}{l}\text { Chronic obstructive pulmonary disease, } \mathrm{n} \\
(\%)\end{array}$ & $60(1.6)$ & $125(3.8)$ & $<0.001$ & $0.070 * *$ \\
\hline Chronic renal disease, $\mathrm{n}(\%)$ & $15(0.4)$ & $14(0.4)$ & 0.825 & $0.003 * *$ \\
\hline Coronary artery disease, $\mathrm{n}(\%)$ & $665(17.5)$ & $990(30.4)$ & $<0.001$ & $0.151 * *$ \\
\hline Crohn's disease, n (\%) & $5(0.1)$ & $3(0.09)$ & 0.733 & $0.006^{* *}$ \\
\hline Diabetes insipidus, $\mathrm{n}(\%)$ & $3(0.08)$ & $1(0.03)$ & 0.629 & $0.010^{* *}$ \\
\hline Dysrhythmias, n (\%) & $319(8.4)$ & $503(15.4)$ & $<0.001$ & $0.109 * *$ \\
\hline Epilepsy, n (\%) & $136(3.6)$ & $137(4.2)$ & 0.181 & $0.016^{* *}$ \\
\hline Glaucoma, n (\%) & $249(9.2)$ & $315(9.7)$ & $<0.001$ & $0.057 * *$ \\
\hline Haemophilia, n (\%) & 0 & 0 & & \\
\hline Hypothyroidism, n (\%) & $1,996(52.7)$ & $509(15.6)$ & $<0.001$ & $0.386^{* *}$ \\
\hline Multiple sclerosis, n (\%) & $2(0.05)$ & $1(0.03)$ & 1.000 & $0.005^{* *}$ \\
\hline Parkinson's disease, n (\%) & $54(1.4)$ & $65(2.0)$ & 0.064 & $0.022 * *$ \\
\hline Rheumatoid arthritis, n (\%) & $70(1.9)$ & $37(1.1)$ & 0.015 & $0.029 * *$ \\
\hline Schizophrenia, n (\%) & $12(0.3)$ & $11(0.3)$ & 0.878 & $0.002^{* *}$ \\
\hline Systemic lupus erythematosus, n (\%) & $5(0.1)$ & $1(0.03)$ & 0.227 & $0.017 * *$ \\
\hline Ulcerative colitis, $\mathrm{n}(\%)$ & $2(0.05)$ & $3(0.09)$ & 0.668 & $0.007 * *$ \\
\hline
\end{tabular}

*Cohen's $d$-value, ${ }^{* *}$ Cramer's $V$. PMB CDL conditions $=$ Prescribed Minimum Benefit Chronic Disease List conditions. Percentages for PMB CDL conditions were calculated using the total number of women $(\mathrm{n}=3$ 791) and men $(\mathrm{n}=3259)$ in the data subset as denominator.

Tables 2 and 3 shows the univariate and age-adjusted odds ratios for the presence of single and two co-present PMB CDL conditions among females compared with males, respectively. Women had higher odds of having hypothyroidism than men (OR, 6.30, 95\% CI; 5.52, 7.19, $p<0.001$ ) (Table 2), which was deemed practically significant. In addition, the presence of hypothyroidism conferred a significant effect on the odds of women experiencing several of the other PMB CDL conditions. For instance, the higher odds of women having rheumatoid arthritis (OR, 1.82, 95\% CI; 1.01, 3.30, $p=0.047$ ) (Table 2 ) were strongly increased in co-presence of hypothyroidism (OR, 4.69, 95\% CI; 1.57, 14.02, $p=0.006$ ), and practically significant.) Furthermore, the odds of women having prevalent asthma, epilepsy, and cardiomyopathy that were near unity and not statistically significant as single PMB CDL conditions (Table 2), increased to be statistically and practically significant in combination with hypothyroidism (Table 3).

Elderly females furthermore had a significant 'advantage' over men against having prevalent cardiovascular conditions (ranging from 1.3 times lower odds for cardiac failure to 1.9 times lower odds for dysrhythmia than men in age-adjusted analysis) (Table 2). This advantage persisted, and increased strongly in the co-presence of other cardiovascular PMB CDL conditions. For instance, the age-adjusted odds of having co-present cardiac failure and dysrhythmia, and co-present coronary artery disease and dysrhythmia were, respectively, 1.9 and 2.4 times lower in women than men from the study population (Table 3). 
Table 2. Odds ratios with $95 \%$ Wald Confidence Intervals (95\% CI) for single Prescribed Minimum Benefit Chronic Disease List (PMB CDL) conditions in patients with concomitant hypertension, diabetes and dyslipidaemia

\begin{tabular}{|c|c|c|c|c|c|}
\hline PMB CDL conditions & $\mathrm{n}$ & $\begin{array}{l}\text { Model 1 } \\
\text { OR [95\% } \\
\text { CI] }\end{array}$ & $p$-value & $\begin{array}{l}\text { Model } 2 \\
\text { aOR [95\% Wald } \\
\text { CI] }\end{array}$ & $p$-value \\
\hline Hypothyroidism & $\begin{array}{l}(1315 \mathrm{~F} \\
282 \mathrm{M})\end{array}$ & $6.30[5.527 .19]$ & $<0.001$ & $6.38[5.587 .28]$ & $<0.001$ \\
\hline Rheumatoid arthritis & $(28 \mathrm{~F}, 18 \mathrm{M})$ & $1.82\left[\begin{array}{ll}1.01 & 3.30\end{array}\right]$ & 0.047 & 1.84 [1.02 3.34] & 0.044 \\
\hline Asthma & $(252 \mathrm{~F}, 264 \mathrm{M})$ & $1.12\left[\begin{array}{lll}0.94 & 1.34]\end{array}\right.$ & 0.204 & $1.14\left[\begin{array}{lll}0.96 & 1.36\end{array}\right]$ & 0.134 \\
\hline Parkinson's disease & $(26 \mathrm{~F}, 31 \mathrm{M})$ & $0.98\left[\begin{array}{ll}0.58 & 1.65\end{array}\right]$ & 0.943 & $0.80\left[\begin{array}{lll}0.47 & 1.35\end{array}\right]$ & 0.398 \\
\hline Epilepsy & $(68 \mathrm{~F}, 84 \mathrm{M})$ & $0.95\left[\begin{array}{lll}0.69 & 1.31\end{array}\right]$ & 0.737 & $0.98\left[\begin{array}{lll}0.71 & 1.35\end{array}\right]$ & 0.891 \\
\hline Cardiac failure & $(323 \mathrm{~F}, 432 \mathrm{M})$ & $0.87\left[\begin{array}{lll}0.75 & 1.01]\end{array}\right]$ & 0.063 & $0.78\left[\begin{array}{lll}0.68 & 0.91\end{array}\right]$ & 0.001 \\
\hline Cardiomyopathy & $(109 \mathrm{~F}, 152 \mathrm{M})$ & $0.84\left[\begin{array}{lll}0.65 & 1.07]\end{array}\right.$ & 0.159 & $0.80\left[\begin{array}{lll}0.63 & 1.03\end{array}\right]$ & 0.087 \\
\hline Schizophrenia & $(7 \mathrm{~F}, 10 \mathrm{M})$ & $0.82\left[\begin{array}{ll}0.31 & 2.15\end{array}\right]$ & 0.685 & $0.82\left[\begin{array}{ll}0.31 & 2.16\end{array}\right]$ & 0.686 \\
\hline Glaucoma & $(128 \mathrm{~F}, 190 \mathrm{M})$ & $0.79\left[\begin{array}{ll}0.63 & 0.98\end{array}\right]$ & 0.036 & $0.71\left[\begin{array}{lll}0.56 & 0.89\end{array}\right]$ & 0.003 \\
\hline Coronary artery disease & $(339 \mathrm{~F}, 617 \mathrm{M})$ & $0.63\left[\begin{array}{lll}0.55 & 0.72]\end{array}\right.$ & $<0.001$ & $0.60\left[\begin{array}{lll}0.52 & 0.69\end{array}\right]$ & $<0.001$ \\
\hline Dysrhythmia & $(108 \mathrm{~F}, 205 \mathrm{M})$ & $0.61\left[\begin{array}{lll}0.48 & 0.77]\end{array}\right]$ & $<0.001$ & $0.54\left[\begin{array}{lll}0.42 & 0.68\end{array}\right]$ & $<0.001$ \\
\hline $\begin{array}{l}\text { Chronic obstructive pulmonary } \\
\text { disorder }\end{array}$ & $(18 \mathrm{~F}, 41 \mathrm{M})$ & $0.51\left[\begin{array}{lll}0.29 & 0.89\end{array}\right]$ & 0.018 & $0.45\left[\begin{array}{lll}0.26 & 0.79\end{array}\right]$ & 0.005 \\
\hline \multicolumn{6}{|c|}{$\begin{array}{l}\text { Data are odds ratios }(\mathrm{OR})(95 \% \text { Wald confidence interval }(\mathrm{CI})) \text {. Conditions with frequencies }(\mathrm{n})<5 \text { were excluded from the analyses. For the } \\
\text { univariate model, the dependent variable was gender }[(\mathrm{female}(1) \text {, male }(0)] \text {, with the type of PMB CDL condition as the independent variable } \\
\text { [with present }(1) \text {, absent }(0)] \text {. } \\
\text { M = Male; F = Female; Model } 1 \text { = Univariate (crude) model; Model } 2 \text { = Age adjusted model; OR = Odds ratio; aOR = Age adjusted odds } \\
\text { ratio }\end{array}$} \\
\hline
\end{tabular}

Table 3. Odds ratios with $95 \%$ Wald Confidence Intervals (95\% CI) for two Prescribed Minimum Benefit Chronic Disease List (PMB CDL) conditions in patients with concomitant hypertension, diabetes and dyslipidaemia

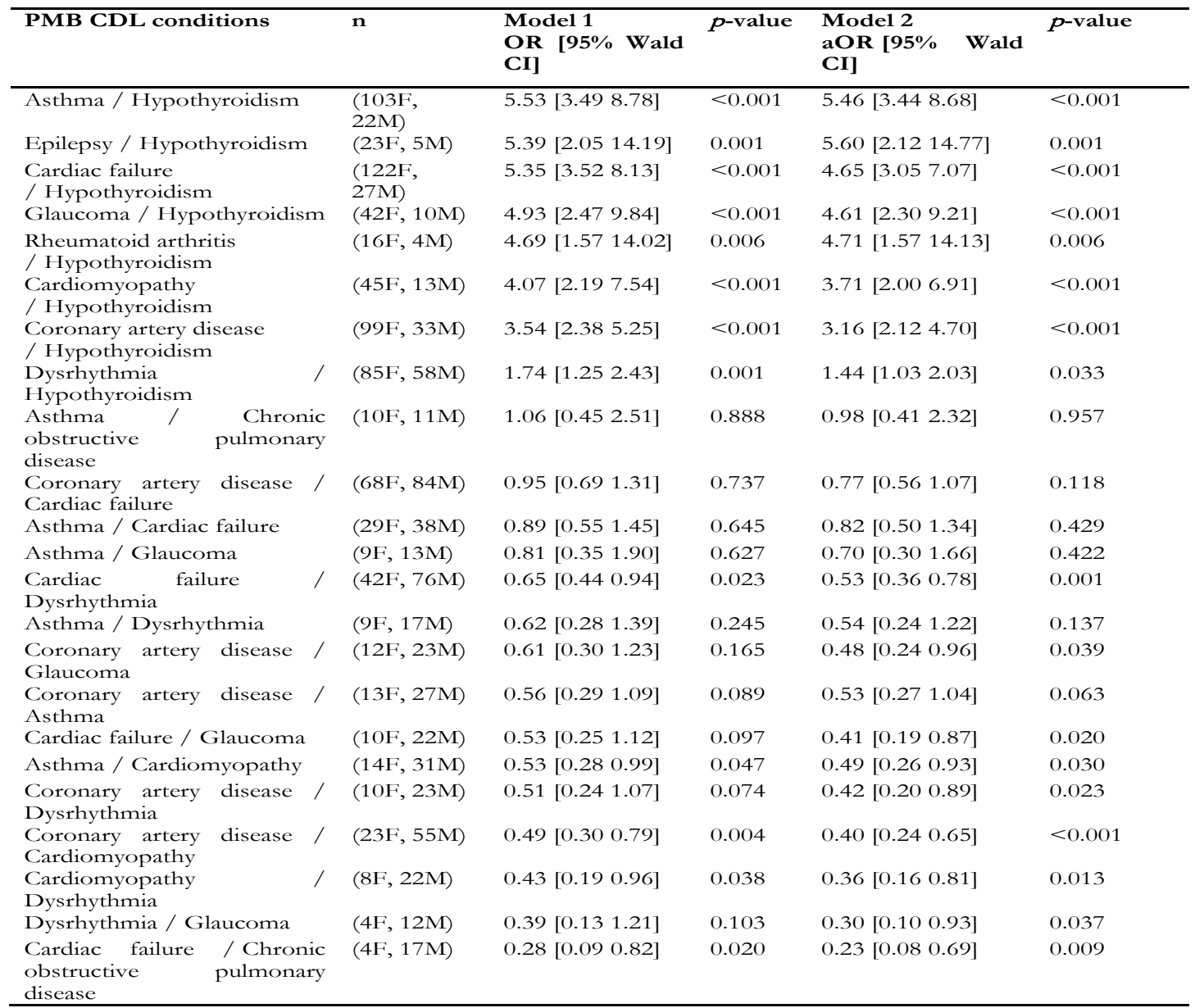
disease

Data are odds ratios (OR) $(95 \%$ Wald confidence interval $(\mathrm{CI}))$. Conditions with frequencies $(\mathrm{n})<5$ were excluded from the analyses. For the univariate model, the dependent variable was gender [(female (1), male (0)], with the type of PMB CDL condition as the independent variable [with present (1), absent (0)].

$\mathrm{M}=$ Male; $\mathrm{F}=$ Female; Model 1 = Univariate (crude) model; Model $2=$ Age adjusted model; OR = Odds ratio; a OR $=$ Age adjusted odds ratio 
In combination with coronary artery disease and dysrhythmia, respectively, the age-adjusted odds for cardiomyopathy were 2.5-2.8 times lower for women than for men (Table 3). It should be noted that this two-combined cardiovascular PMB CDL conditions were present in only 416 of the 17,866 patients from our study population (prevalence ratio (male:female) 1.7). Moreover, co-present hypothyroidism not only reversed the apparent 'advantage' afforded by being female against prevalent cardiovascular disease (e.g. cardiac failure, cardiomyopathy, coronary artery disease and dysrhythmia) (Table 2 ), but increased the odds considerably (Table 3). The odds for the co-presence of hypothyroidism with cardiac failure (OR, 5.35, 95\% CI; 3.52, 8.13, $p<0.001)$ and cardiomyopathy (OR, 4.07, 95\% CI; 2.19, 7.54, $p<0.001$ ), respectively, were deemed practically significant.

\section{Discussion}

This large cross-sectional study of medical claims data revealed that a nearly $40 \%$ of patients with concomitant hypertension, diabetes and dyslipidaemia presented with several of the other Prescribed Minimum Benefit Chronic Disease List (PMB CDL) conditions. We further found that hypothyroidism was the single most prevalent PMB CDL condition encountered by about four times more in women than men. These findings are in line with trends in international literature showing that hypothyroidism may be up to 10 times more frequent in women than men, ${ }^{36-39}$ especially among adults in middle age and in the elderly. ${ }^{39-40}$ The relatively high prevalence of hypothyroidism in elderly women from our study population furthermore accords with recent studies suggesting an association between thyroid disease and the several of the traits for the metabolic syndrome. ${ }^{41-46}$ This association in older adults may be ascribed to the pathophysiology of thyroid hormone functions on lipid and glucose metabolism, and blood pressure. It has also been suggested that abnormalities in thyroid function may be secondary to weight excess. ${ }^{47-50}$ These functions are beyond the scope of this manuscript. It is, however, conceivable that women from our study population showed a higher likeliness for hypothyroidism compared with their male counterparts. Evidence in support of this includes the data from the 2012 SANHANES-1 demonstrating that $64 \%$ of women in contrast to $31 \%$ of men older than 15 years in South Africa are either overweight or obese. ${ }^{4}$ One in ten South African males furthermore had a waist circumference equal to or larger than $102 \mathrm{~cm}$, while more than half of females had a waist circumference equal to/or larger than $88 \mathrm{~cm}$. In addition, the overall prevalence of familial hypercholesterolemia in South Africa was estimated as high as 1:7 compared with 1:500 worldwide. ${ }^{51}$ Almost one out of four participants from the 2012 SANHANES-1 demonstrated an abnormally high serum total-, and LDL-cholesterol, and one out of two had abnormally low HDL-cholesterol. This prevalence of abnormal serum total- and LDL-cholesterol was higher among females than males. ${ }^{4}$ Females partaking in the SANHANES-1 furthermore had significantly higher self-reported high blood pressure and high blood sugar rates than males. Overall, one out five participants older than 45 years of age had hypertension. Another one out of five participants had impaired glucose homeostasis, whereas one out of ten participants had diabetes. Both impaired glucose homeostasis and diabetes prevalence increased with age, reaching a peak in the groups aged 45-54 years and 55-64 years. ${ }^{4}$

Our results furthermore showed that being female accorded a protective effect against prevalent cardiovascular conditions (cardiac failure, cardiomyopathy, coronary artery disease and dysrhythmias). In combination with hypothyroidism, however, this advantage was reversed, and the odds strongly increased. The metabolic syndrome represents a major risk factor for the development of CVD. ${ }^{18,52-53}$ The magnitude of this increased risk burden varies according to which components of the syndrome are present, ${ }^{53}$ as well as to the number of components present. ${ }^{54}$ The contribution of several metabolic disorders to the metabolic syndrome is different in men and women. ${ }^{55,56}$ These gender differences may contribute towards gender differences in CVD. ${ }^{57-59}$ Hypothyroidism per se represents a risk factor for the development of cardiovascular disease. ${ }^{60-63}$ Because both metabolic syndrome and hypothyroidism are independent risk factors for cardiovascular disease, it is possible that patients suffering from both these disease entities may have a compounded risk. It is therefore possible that patients from our study population with at least three of the metabolic syndrome traits (i.e. concomitant hypertension, diabetes and dyslipidaemia) with / and hypothyroidism showed a higher likeliness for cardiovascular disease. It should be noted, however, that potential effect modification and confounding were outside the scope of the current descriptive analyses, and therefore not considered in this paper. 


\section{Strengths and limitations}

The study population comprised of patients from the South African private health sector, registered as beneficiaries of several medical schemes. This limits the external validity of the study in that results cannot be generalised to the total South African population. Furthermore, the presence of confounding variables on the database, such as severity of illness, smoking status, patients' socio-economic status, ethnicity, family history of illness, and alcohol use, medical scheme the patient belonged to, and plan type/option was not recorded on research database and hence, could not be controlled for. The database, however, did contain pharmaceutical claims data for a total of 974,497 patients at baseline, thereby increasing the power and accuracy for sub-group analyses. Furthermore, there was no missing data fields in the data set. Data quality was ascertained by several automated validation processes that were applied in-house by the PBM, such as data integrity validation and eligibility services, utilization management services, clinical management services and pricing management along with real-time benefit management.

To increase the validity of the diagnoses and to avoid counting transitory or accidental diagnoses, we counted only PMB CDL conditions if they were coded in association with claims paid from a patient's PMB benefits. The PMBs were developed to ensure that all medical scheme members have access to certain minimum health services, regardless of the benefit option they have selected. ${ }^{14,15}$ There is certainly always the probability that some patients' data may not been have recorded on the claims database for reimbursement because of prescribers following a different treatment regimen than that published in the algorithms, resulting in patients paying out-of-pocket for expenses for medication associated with the treatment of the PMB CDLs. This may lead to under ascertainment in the prevalence of PMB CDL conditions in these patients. We, however, assumed that this would be only a small percentage of patients because medical schemes are obliged to cover the costs related to the diagnosis, treatment and on-going care of the PMB CDL conditions, irrespective of the patients' medical plan or option.

\section{Conclusion}

The findings of this large cross-sectional study revealed strong associations of several of the Prescribed Minimum Benefit Chronic Disease List conditions among patients with concomitant hypertension, diabetes and dyslipidaemia, indicating gender as determining factor for these types of conditions. Concomitant hypertension, diabetes and dyslipidaemia indicating gender as determining factor for these types of conditions. This is, to our knowledge, the first time that these associations were assessed using claims data in South Africa. We were furthermore able to support clinically derived knowledge by using medicine claims data, with the recognition of hypothyroidism as an important discriminating factor for co-morbidity in women with concomitant hypertension, diabetes and dyslipidaemia in particular with cardiovascular disease. Longitudinal research is clearly needed to reveal the timeline for the development of this condition and its causal inferences with the defining risk factors specific to the metabolic syndrome. This will enable health care practitioners to exercise pro-active care. By being pro-active in the management of patients with multiple co-morbidities, disease burden and potential health care costs can be limited.

Control of health care expenditure in the next decade will be one of the major challenges facing the South African economy with escalating costs identified as a key threat to future reforms in the South African health care industry. ${ }^{64,65}$ With the current lack of electronically captured resource utilization data in the public sector, data collected from the private sector can be used to generate forecasts with well-characterized accuracies about the future or diagnoses about states of a patient that cannot be inspected directly. ${ }^{66,67}$ Considering that the PMB CDL includes chronic conditions for which medical schemes are compelled to provide benefits and full management payment with no co-payments, ${ }^{14,15}$ such data is fundamental to planning and decision-making in South African health departments, especially when planning the implementation of a National Health Insurance System as is currently mooted by government.

\section{References}

1. Salisbury C. Multimorbidity: redesigning health care for people who use it. Lancet 2012; 380(9836):7-9. PubMed

2. United Nations. Department of Economics and Social Affairs. Population Division. World population 2012. [homepage on the internet] c2012 [cited 2014 July 4]. Available from www.unpopulation.org

3. World Health Organization. The Global Burden of Disease: 2004 Update. Geneva: WHO; 2008. 
4. Shisana O, Labadarios D, Rehle T, et al. South African National Health and Nutrition Examination Survey (SANHANES-1): 2014 Edition. Cape Town: HSRC Press; 2014.

5. Barnett K, Mercer SW, Norbury M, Watt G, Wyke S, Guthrie B. Epidemiology of multimorbidity and implications for health care, research, and medical education: a cross-sectional study. Lancet 2012;380(9836):37-43. PubMed

6. Van Weel C. Chronic diseases in general practice: the longitudinal dimension. Eur J Gen Pract. 1996;2(1):17-21. PubMed

7. Fried LP, Bandeen-Roche K, Kasper JD, Guralnik JM. Association of comorbidity with disability in older women: the Women's Health and Aging Study. J Clin Epidemiol. 1999;52:27-;37. PubMed

8. c2010 [cited 2011 Feb 01]. Available from http://www. medicalschemes.com/ReadNews.aspx?2

9. Marengoni A, Angleman S, Melis R, Mangialasche F, Karp A, Garmen A, et al. Aging with multimorbidity: a systematic review of the literature. Ageing Res Rev. 2011;10(4):430-439.

10. McLeod H. National Health Insurance Policy brief 3: The impact of chronic disease on future NHI [homepage on the internet]. c2009 [cited 2012 Aug 31]. Available from http://www.imsa.org.za/national-health-insurance/policy-briefs/

11. Still L. Health care in South Africa. Pietermaritzburg: Intrepid printers; 2009.

12. Council for Medical Schemes. Annual report 2010-

2011. [homepage on the internet] c2011 [cited 2014 July 4]. Available from www.medicalschemes.com

13. Mayosi BM, Flisher AJ, Lalloo UG, Sitas F, Tollman SM, Bradshaw D. The burden of non-communicable diseases in South Africa. Lancet. 2009;374(9693):934 PubMed -947.

14. Council for Medical Schemes, South Africa. Prescribed minimum benefits (PMB's) aim to provide you with continuous care [homepage on the internet]. c2010 [cited 2011 Feb 01]. Available from http://www.medicalschemes.com/ReadNews.aspx?2

15. Council for Medical Schemes, South Africa. Medical Schemes Act, 131 of 1998. [homepage on the internet] c1998 [cited 2014 Feb 01]. Available from https://www. medicalschemes.com/Content.aspx?130

16. Schäfer I, von Leitner E-C, Schön G, Koller D, Hansen $\mathrm{H}$, Kolonko $\mathrm{T}$, et al. Multimorbidity patterns in the elderly: A new approach of disease clustering identifies complex interrelations between chronic conditions. PLoS One 2010; 5(12):e15941. PubMed

17. Kirchberger I, Meisinger C, Heier M, Zimmermann AK, Thorand B, Autenrieth CS, et al. Patterns of multimorbidity in the aged population. Results from the KORA-Age study. PLoS One 2012; 7(1): e30556. PubMed 18. Grundy SM. Metabolic syndrome: a multiplex cardiovascular risk factor. J Clin Endocrinol Metab 2007; 92(2):399-404.

19. Grundy SM, Cleeman JI, Daniels SR, Donato KA, Eckel RH, Franklin BA, et al. Diagnosis and management of the metabolic syndrome: an American Heart Association/National Heart, Lung, and Blood Institute Scientific statement. Circulation 2005; 112(17):2735-2752. PubMed 20. Cameron AJ, Shaw JE, Zimmet PZ. The metabolic syndrome: prevalence in worldwide populations. Endocrinol Metab Clin North Am 2004; 33(2):351-375.

21. Schwellnus, MP, Patel DN, Nossel CJ, Dreyer M, Whitesman S, Derman EW. Healthy lifestyle interventions in general practice. Part 6: lifestyle and metabolic syndrome. S Afr fam prac. 2009;51(3):177 PubMed -181.

22. Motala AA, Mbanya JC, Ramaiya KL. Metabolic syndrome in sub-Saharan Africa. Ethn Dis 2009;19(Suppl. 2):S2.8-S2.10.

23. Jennings CL, Lambert EV, Collins M, Levitt NS, Goedecke JH. The atypical presentation of the metabolic syndrome components in black African women: the relationship with insulin resistance and the influence of regional adipose tissue distribution. Metabolism. 2009;58(2):149 PubMed -157.

24. Council for Medical Schemes. Annual report 20082009. [homepage on the internet] c2009 [cited 2014 July 4]. Available from www.medicalschemes.com

25. Snyman J, editor. MIMS Desk Reference annual (MDR). Saxonwold: CTP printers; 2008.

26. Cameron AJ, Shaw JE, Zimmet PZ. The metabolic syndrome: prevalence in worldwide populations. Endocrinol Metab Clin North Am 2004; 33(2):351-375.

27. Ervin RB. Prevalence of metabolic syndrome among adults 20 years of age and over, by sex, age, race and ethnicity, and body mass index: United States, 2003-2006. Natl Health Stat Report 2009; 13(13):1-7.

28. Procopiou M, Philippe J. The metabolic syndrome and type 2 diabetes: epidemiological figures and country specificities. Cerebrovasc Dis 2005; 20(Suppl 1):S2-S8.

29. Wild SH, Byrne CD. The epidemiology of the metabolic syndrome and its association with diabetes, cardiovascular disease and other conditions. In: Byrne CD, Wild 
SH, editors. The Metabolic syndrome. 2nd ed. Chichester: Wiley-Blackwell, 2011; p. 1-18.

30. Morley JE, Sinclair A. The metabolic syndrome in older persons: a loosely defined constellation of symptoms or a distinct entity? Age Ageing 2009; 38(5):494-497. PubMed

31. Wolff JL, Starfield B, Anderson G. Prevalence, expenditures, and complications of multiple chronic conditions in the elderly. Arch Intern Med 2002; 162(20):22692276. PubMed

32. Fortin M, Bravo G, Hudon C, Vanasse A, Lapointe L. Prevalence of multimorbidity among adults seen in family practice. Ann Fam Med 2005; 3(3):223-228. PubMed 33. Piccirillo JF, Vlahiotis A, Barrett LB, Flood KL, Spitznagel EL, Steyerberg EW. The changing prevalence of comorbidity across the age spectrum. Crit Rev Oncol Hematol 2008; 67(2):124-132.

34. Steyn HS. Manual for the determination of effect size indices and practical significance homepage on the Internet]. c2009 [updated 2012 Feb; cited 2012 Sept 25]. Available from http://www.nwu.ac.za/content/statcs-effect-size

35. SAS for Windows [computer program]. Version 9.3. Cary (NC): SAS Institute Inc.; 2010.

36. American College of Physicians. Clinical guideline, part 1. Screening for thyroid disease. Ann Intern Med 1998;129(2):141-143. PubMed

37. Vanderpump MPJ. Epidemiology of thyroid dysfunction - hypothyroidism and hyperthyroidism. Br Med Bull 2011; 99(1):39-51. PubMed

38. Vanderpump MPJ. The epidemiology ofthyroid diseases. In: Braverman LE, Utiger RD, editors. Werner and Ingbar's The Thyroid: A Fundamental and Clinical Text. 9th ed. Philadelphia: JB Lippincott-Raven, 2005; p. 398496.

39. Díez JJ, Iglesias P. Hypothyroidism in the middle aged and elderly: clinical aspects. In: Preedy VR, Burrow GN, Watson R, editors. Comprehensive handbook of iodine. Nutritional, biochemical, pathological and therapeutic aspects. San Diego (CA): Academic press, 2009; p. 1033-1039.

40. Park HT, Cho GJ, Ahn KH, Shin JH, Hong SC, Kim $\mathrm{T}$, et al. Thyroid stimulation hormone is associated with metabolic syndrome in euthyroid postmenopausal women. Maturitas 2009;301-305.

41. Lai Y, Wang J, Jiang F, Wang B, Chen Y, Li M, et al. The relationship between serum thyrotropin and compo- nents of metabolic syndrome. Endocr J 2001;58(1):23-30. PubMed

42. Iven KA, Schröder E, Brabant G. Thyroid hormones and the metabolic syndrome. Eur Thyroid J 2013;2:83-92 PubMed .

43. Erdogan M, Canataroglu A, Ganidagli S, Kulaksızoglu M. Metabolic syndrome prevalence in subclinic and overt hypothyroid patients and the relation among metabolic syndrome parameters. J Endocrinol Invest 2011; 34(7):488 PubMed -492.

44. Waring AC, Rodondi N, Harrison S, Kanaya AM, Simonsick EM, Miljkovic I, et al. Thyroid function and prevalent and incident metabolic syndrome in older adults: the Health, Ageing and Body Composition Study. Clin Endocrinol (Oxf) 2012; 76(6):911-918. PubMed

45. Meher LK, Raveendranathan SK, Kota SK, Sarangi J, Jali SN. Prevalence of hypothyroidism in patients with metabolic syndrome. Thyroid Res Pract 2013; 10(2):60-64. PubMed

46. Silva JE. Thermogenic mechanism and their hormonal regulation. Physiol Rev 2006;86:435-464 PubMed .

47. Rosenbaum M, Hirsch J, Murphy E, Leibel RL. Effects of changes in body weight on carbohydrate metabolism, catecholamine excretion and thyroid function. $\mathrm{Am}$ J Clin Nutr 2000;71:1421-1432 PubMed.

48. De Pergola G, Ciampolillo A, Paolotti S, Trerotoli P, Giorgino R. Free triiodothyronine and thyroid stimulating hormone are directly associated with waist circumference, independently of insulin resistance, metabolic parameters and blood pressure in overweight and obese women. Clin Endocrinol (Oxf) 2007; 67(2):265-269. PubMed

49. Longi S, Radetti G. Thyroid function and obesity. $J$ Clin Res Pediatr Endocrinol 2013;5(Suppl 1):40-44.

50. Steyn K, Fourie JM, Shepherd J. Detection and measurement of hypercholesterolaemia in South Africans attending general practitioners in private practice - the cholesterol monitor. S Afr Med J 1998; 88(12):1569-1574. PubMed

51. Maritz FJ. Dyslipidaemia in South Africa. In: Steyn K, Fourie J, Temple N, editors. Chronic diseases of lifestyle in South Africa: 1995-2005. South Africa: Medical Research Council, 2006; p. 97-108.

52. Galassi A, Reynolds K, He J. Metabolic syndrome and risk of cardiovascular disease: a meta-analysis. Am J Med 2006; 119(10):812-819. PubMed

53. Grundy SM. Metabolic syndrome: connecting and reconciling cardiovascular and diabetes worlds. J Am Coll Cardiol 2006; 47(6):1093-1100. PubMed 
54. Scholze J, Alegria E, Ferri C, Langham S, Stevens W, Jeffries D, et al. Epidemiological and economic burden of metabolic syndrome and its consequences in patients with hypertension in Germany, Spain and Italy; a prevalence-based model. BMC Public Health 2010; 10:529.

55. Dallongeville J, Cottel D, Arveiler D, Tauber JP, Bingham A, Wagner A, et al. The association of metabolic disorders with the metabolic syndrome is different in men and women. Ann Nutr Metab 2004; 48(1):43-50. PubMed 56. Beigh SH, Jain S. Prevalence of metabolic syndrome and gender differences. Bioinformation 2012; 8(13):613616. PubMed

57. Kuk JL, Ardern CI. Age and sex differences the clustering of metabolic syndrome factors: association with mortality risk. Diabetes care 2010; 33(11):2457-2461. PubMed

58. Regitz-Zagrosek V, Lehmkuhl E, Weickert MO. Gender differences in the metabolic syndrome and their role for cardiovascular disease. Clin Res Cardiol2006; 95(3):136147. PubMed

59. Pérez-López FR, Larrad-Mur L, Kallen A, Chedraui P, Taylor HS. Gender Differences in Cardiovascular Disease: Hormonal and Biochemical Influences. Reprod Sci 2010; 17(6):511-531. PubMed

60. Rodondi N, den Elzen WP, Bauer DC, Cappola AR, Razvi S, Walsh JP, et al. Subclinical hypothyroidism and the risk of coronary heart disease and mortality. JAMA 2010; 304(12):365-374. PubMed
61. Rodondi N, Newman AB, Vittinghoff E, de Rekeneire N, Satterfield S, Harris TB, et al. Subclinical hypothyroidism and the risk of heart failure, other cardiovascular events, and death. Arch Intern Med 2005; 165(21):24602466. PubMed

62. Nanchen D, Gussekloo J, Westendorp RG, Stott DJ, Jukema JW, Trompet S, et al. Subclinical thyroid dysfunction and the risk of heart failure in older persons at high cardiovascular risk. J Clin Endocrinol Metab 2012; 97(3):852-861.

63. Mayer Jr O, Šimon J, Filipovský J, Plásková M, Pikner R. Hypothyroidism in coronary heart disease and its relation to selected risk factors. Vasc Health Risk Manag 2006; 2(4):499-506.

64. Ayankogbe O. Building capacity for African primary care research. Afr J Prm Health Care Fam Med 2014;6(1). 65. National Planning Commission. Promoting health. National Development Plan 2030: Our future - make it work. [homepage on the Internet] c2012 [cited 2014 Jun 26]. Available from www.gov.za/documents/download. php?f $=154437$.

66. Garrib A, Stoops N, McKenzie A, Dlamini L, Govender $\mathrm{T}$, Rohde $\mathrm{J}$, et al. An evaluation of the district health information system in rural South Africa. Afr Med J 2008;98:549-552 PubMed.

67. Cline GB, Luiz JM. Information technology systems in public sector health facilities in developing countries: the case of South Africa. BMC Med Inform Decis Mak 2013;13:13. 